\title{
Relationship between Serum Levels of Some Trace Elements, Disease Duration and Severity in Patients with Knee Osteoarthritis
}

\author{
Naza M. A. Mahmood \\ Department of Pharmacology and Toxicology, School of Pharmacy, Faculty of Medical Sciences, \\ Sulaimani University, Kurdistan, Iraq \\ Email: naza.ali@univsul.edu.iq
}

Received 17 September 2015; accepted 9 November 2015; published 12 November 2015

Copyright (c) 2015 by author and Scientific Research Publishing Inc.

This work is licensed under the Creative Commons Attribution International License (CC BY). http://creativecommons.org/licenses/by/4.0/

(c) $($ )

\begin{abstract}
Background: Many trace elements in the biological system, including boron, are involved in various vital processes related to health and diseases. Boron has been proved to have a role in decreasing inflammatory pain, joint stiffness and other disabling symptoms associated with osteoarthritis (OA). Aims and Objective: The purpose of the present study was to evaluate the relationship between serum concentrations of copper ( $\mathrm{Cu}$ ), zinc ( $\mathrm{Zn})$, selenium (Se), manganese (Mn) and magnesium (Mg) with disease duration and severity in patients with knee OA. Methods: A total of 43 patients with knee $\mathrm{OA}$ were clinically evaluated and serum concentrations of $\mathrm{Cu}, \mathrm{Zn}, \mathrm{Se}$, $\mathrm{Mn}$ and Mg were measured, and the results were compared with those of healthy controls. Trace elements levels were correlated with disease duration and severity. Results: Serum $\mathrm{Cu}$ and the value of $\mathrm{Cu} / \mathrm{Zn}$ were significantly elevated in $\mathrm{OA}$ patients and positively correlated with disease duration and severity. Serum $\mathrm{Zn}$, Se and Mn were significantly lower in patients compared with controls; $\mathrm{Zn}$ and Se were found to be negatively and significantly correlated with disease duration and severity. Conclusion: Patients with knee $\mathrm{OA}$ had higher levels of $\mathrm{Cu}$ and larger value of $\mathrm{Cu} / \mathrm{Zn}$ and lower levels of serum $\mathrm{Zn}$ and Se; these changes were potentially correlated with the duration and severity of disease.
\end{abstract}

\section{Keywords}

Knee OA, Trace Elements, Disease Severity, Disease Duration

\section{Introduction}

Osteoarthritis (OA) is a chronic disorder characterized by progressive degenerative changes in the cartilage and 
articular tissues. Multiple etiologies are suspected to contribute to the formation of OA, including defective articular cartilage structure and biosynthesis, joint trauma, joint instability, congenital and developmental abnormalities, and inflammatory conditions [1]. Oxidative damage to essential cell components caused by oxygen free radicals is a mechanism in the pathobiology of degenerative joint disease [2]. Many trace elements have been recognized to play an important role in the pathogenesis and progression of many diseases, including osteoarthritis. However, it is difficult to precisely identify the relationship between these elements and disease severity because of the multifactorial variations of these elements in the biological fluids [3] [4]. A relationship was observed between OA and trace elements in many research studies. In many cases, changes in the metabolism of these elements were demonstrated. Naturally occurring minerals such as magnesium $(\mathrm{Mg})$, copper $(\mathrm{Cu})$, manganese (Mn), selenium (Se) and zinc (Zn) have shown anti-inflammatory effects in both animal and human studies. Animal model of OA, a deficiency of dietary Mg was shown to accelerate cartilage damage [5]. Furthermore, increased intake of dietary Mg may influence inflammation through decreasing the release of C-reactive protein [6]. Copper is an essential cofactor in enzymes such as super oxide dismutase (SOD) that also needs Zn and $\mathrm{Mn}$ as cofactors. Many studies revealed a role for oxidative stress in the pathogenesis of OA, whereby ROS generation and impaired antioxidant status of the joint might result in the degradation of cartilage joint remodeling [7]. Selenium is also an essential co-factor for glutathione peroxidase which may have a role in reducing the incidence of osteoarthritic lesion [8]. Positive roles have also been suggested for trace minerals such as boron and manganese in reducing the symptoms and slowing the pathogenesis of OA [9]. It is not known whether trace element status leads to disease or whether diseases set in due to the deficiency of trace elements. Although it is generally believed that a strict metabolic control delays the development of late complications OA.

\section{Methods}

A total of 43 knee OA patients and 18 controls were enrolled in this case-control study between December 2014 and April 2015. The controls were selected to have similar age and gender distributions compared to those of the knee OA patients. The knee OA patients were diagnosed according to the ACR Guidelines for Medical Management of Osteoarthritis of the knee 2000 [10] by senior orthopedist, and patients were excluded from the study if they had comorbid diseases that affect immunity, or overlapped with other connective tissue diseases, or were alcohol drinker, or received a systemic therapy which may interfere with the inflammatory condition for the last 4 weeks before blood sample collection, and pregnant women. All controls were free of remarkable musculoskeletal disorders by medical history, physical and laboratory examinations. Patients also underwent clinical examinations and record disease duration, while disease severity score was calculated according to the Ahlback classification and the Kellgren and Lawrence system [11] [12]. All subjects were mainland Kurdish ethnicity and gave written informed consent for the study under a protocol approved by the ethics board of the Faculty of Medical Sciences, Sulaimani University.

Fasting blood samples were collected in plain tubes and centrifuged for $15 \mathrm{~min}$ at $1500 \mathrm{rpm}$ at room temperature. After centrifugation, serum samples were collected and stored at $-20^{\circ} \mathrm{C}$ until analysis. Hemolyzed samples were excluded from the study. Utmost care was taken to avoid potential pre-analytical contamination during specimen acquisition and treatment. A conventional wet acid digestion method was used to digest serum as previously described [13]. Briefly, $0.4 \mathrm{ml}$ of serum sample and $3 \mathrm{ml}$ of nitric acid (65\%) were added into a $25 \mathrm{ml}$ beaker, and digested at $70^{\circ} \mathrm{C}-80^{\circ} \mathrm{C}$ on an electric hot plate for $90 \mathrm{~min}$. Thereafter, $1.5 \mathrm{ml}$ of hydrogen peroxide (30\%) was added into the beaker and continued for digestion. When the remaining volume was about $0.5-1 \mathrm{ml}$, the liquid was all transferred into a $5 \mathrm{ml}$ of volumetric flask after cooling, and a final volume of $5 \mathrm{ml}$ was obtained by adding the nitric acid stock standard solution. The reference material was treated in the same manner before analysis. ICP atomic absorption spectrophotometer (Perkin Elmer, USA) was used for determination of serum $\mathrm{Cu}, \mathrm{Zn}, \mathrm{Se}, \mathrm{Mn}$ and $\mathrm{Mg}$ concentrations according to standard procedures. All the results were expressed as mean \pm SD. The data were analyzed by using Graph Pad Prism 5.1 software (Graph Pad Software Inc., San Diego, CA, USA). Unpaired $t$-test with Welch's correction was utilized for statistical evaluation of the differences between the means. The correlation between element and disease duration and severity and $\mathrm{Cu} / \mathrm{Zn}$ ratio was detected by Spearman correlation analysis. Difference was considered significant if $P$ value (FDR corrected) $<0.05$.

\section{Results}

Table 1 indicates that serum concentrations of $\mathrm{Zn}$, Se and Mn were significantly decreased $(P<0.0001)$ in OA 
patients group compared with that in controls (137\%, 66\% and 27\%, respectively). Meanwhile, serum Cu concentrations in OA patients were significantly elevated $(129 \%$; $P<0.0001)$ compared with that reported in control group. Table 1 also shows serum Mn concentrations were not significantly changed in OA patients $(P>$ 0.05 ). Additionally, $\mathrm{Cu} / \mathrm{Zn}$ ratio was highly and significantly elevated in OA patients (595\%; $P<0.0001)$ compared with control group. Figure 1 shows the correlation between duration of OA in the patients group with se-

Table 1. Serum levels of zinc, copper, selenium, manganese, and magnesium, and copper/ration in patients with knee OA compared with healthy subjects.

\begin{tabular}{|c|c|c|c|}
\hline Element & Control subjects $(n=18)$ & OA patients $(n=43)$ & $P$ value \\
\hline Serum Zinc $(\mu \mathrm{g} / \mathrm{ml})$ & $2.1 \pm 0.54$ & $0.73 \pm 0.17$ & $<0.0001$ \\
\hline Serum Copper $(\mu \mathrm{g} / \mathrm{ml})$ & $1.33 \pm 0.35$ & $3.05 \pm 0.81$ & $<0.0001$ \\
\hline Serum Selenium $(\mu \mathrm{g} / \mathrm{ml})$ & $0.16 \pm 0.03$ & $0.054 \pm 0.002$ & $<0.0001$ \\
\hline Serum Manganese $(\mu \mathrm{g} / \mathrm{ml})$ & $0.64 \pm 0.06$ & $0.47 \pm 0.11$ & $<0.001$ \\
\hline Serum Magnesium $(\mu \mathrm{g} / \mathrm{ml})$ & $18.9 \pm 2.3$ & $18.01 \pm 1.7$ & 0.16 \\
\hline Copper/Zinc ratio & $0.69 \pm 0.29$ & $4.8 \pm 3.1$ & $<0.0001$ \\
\hline
\end{tabular}

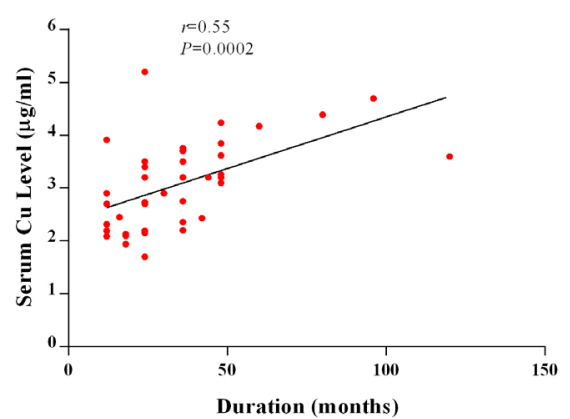

(a)

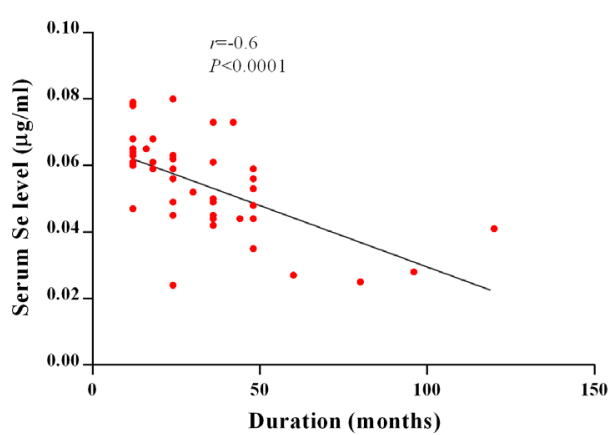

(c)

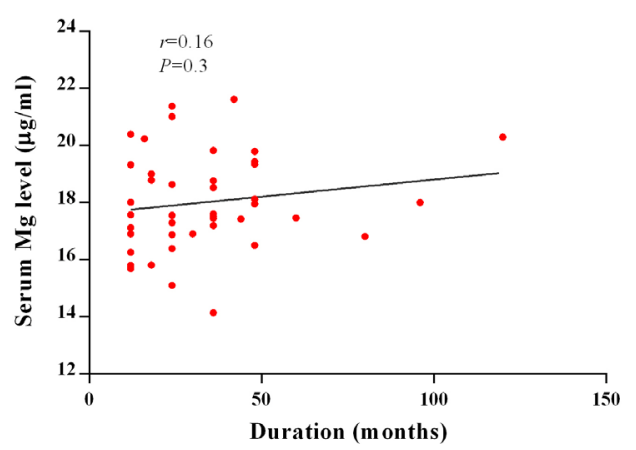

(e)

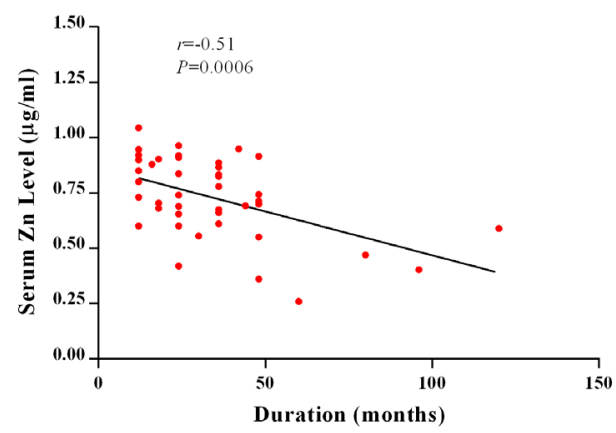

(b)

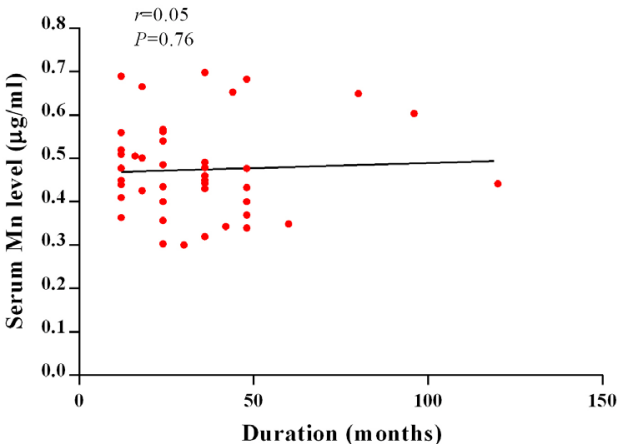

(d)

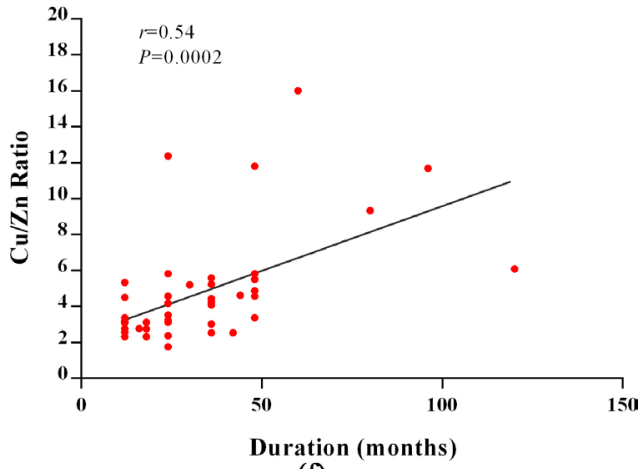

(f)

Figure 1. Correlation between disease duration and serum levels of trace elements and $\mathrm{Cu} / \mathrm{Zn}$ ratio in patients with knee OA; $r=$ Spearman correlation coefficient; significance at $P<0.05$. 
rum concentrations of trace elements, and strong positive and significant correlation was reported ((a) and (f)) with serum $\mathrm{Cu}$ and $\mathrm{Cu} / \mathrm{Zn}$ ratio ( $r=0.55$ and $r=0.54$, respectively). Meanwhile, strong negative correlation was reported with serum concentrations of Zn and Se ((b) and (c)) ( $r=-0.51$ and $r=-0.6$, respectively. In the same regard, Figure 1 indicates weak and non-significant correlation between disease duration and serum concentrations of $\mathrm{Mn}$ and $\mathrm{Mg}((\mathrm{d})$ and (e)) ( $r=0.05$ and $r=0.16$, respectively). In Figure 2, serum concentrations of $\mathrm{Cu}$ and $\mathrm{Cu} / \mathrm{Zn}$ ratio ((a) and (f)) were highly and positively correlated with the disease severity score $(r=0.89$ and $r$ $=0.86$, respectively), while serum concentrations of $\mathrm{Zn}$ and Se (b) and (c)) were highly and negatively correlated with disease severity score ( $r=-0.77$ and $r=-0.91$, respectively). Moreover, weak and non-significant correlations were reported with serum concentrations of $\mathrm{Mn}$ and $\mathrm{Mg}(r=0.006$ and $r=0.08$, respectively) (Figure 2(d) and Figure 2(e)). In Figure 3(a), serum concentration of Se was highly and negatively correlated with the $\mathrm{Cu} / \mathrm{Zn}$ ratio $(r=-0.81)$ while poor negative and non-significant correlation was reported for serum $\mathrm{Mn}$ concentrations (Figure 3(b)) with $\mathrm{Cu} / \mathrm{Zn}$ ratio $(\mathrm{r}=-0.04)$.

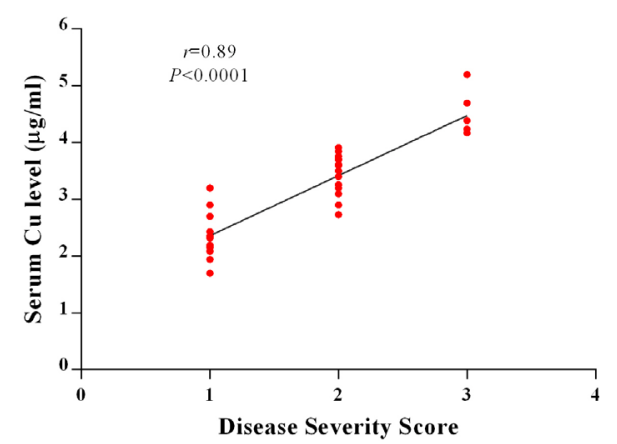

(a)

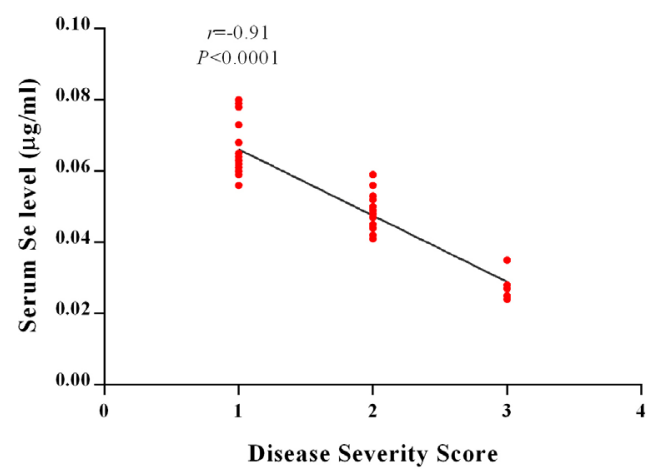

(c)

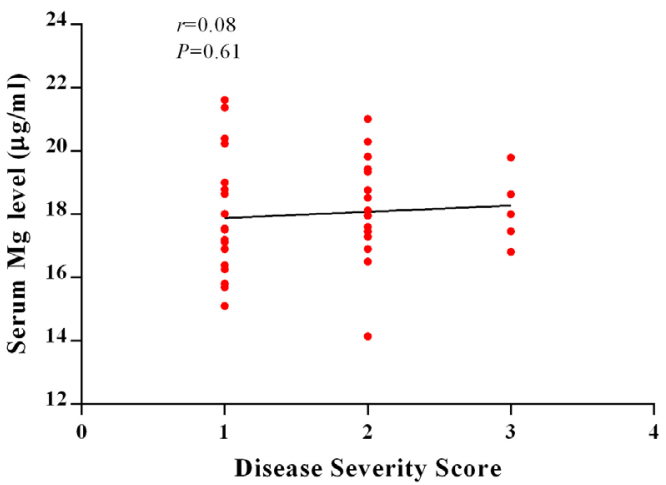

(e)

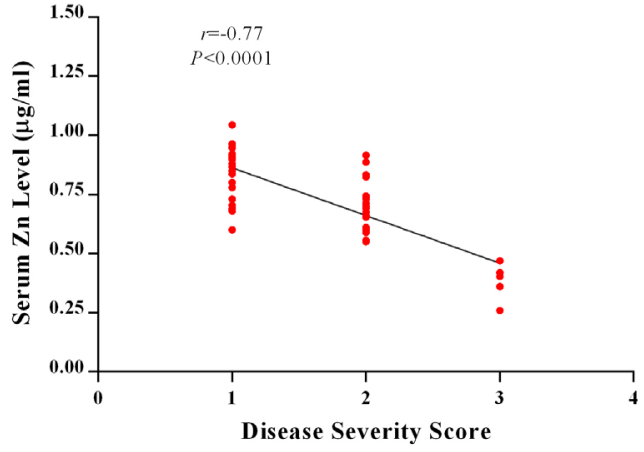

(b)

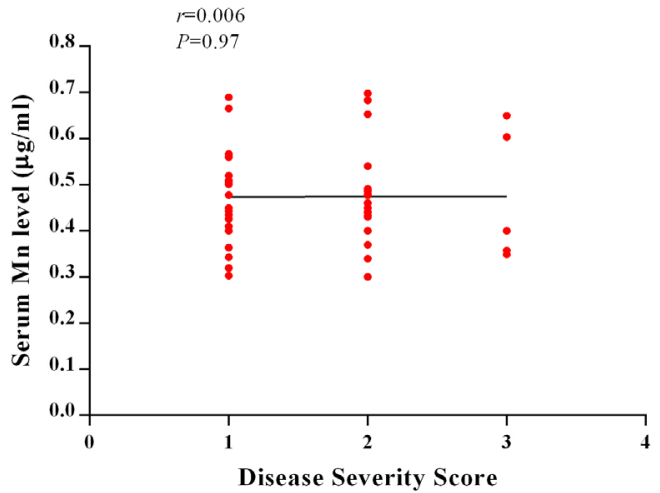

(d)

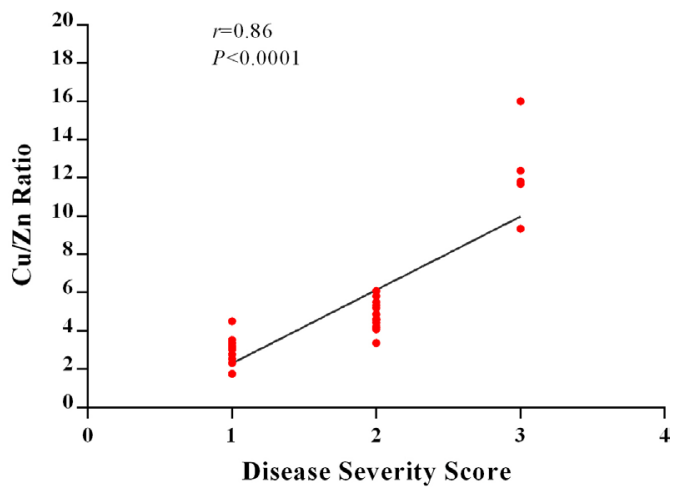

(f)

Figure 2. Correlation between disease severity score and serum levels of trace elements and $\mathrm{Cu} / \mathrm{Zn}$ ratio in patients with knee OA; $r=$ Spearman correlation coefficient; significance at $P<0.05$. 


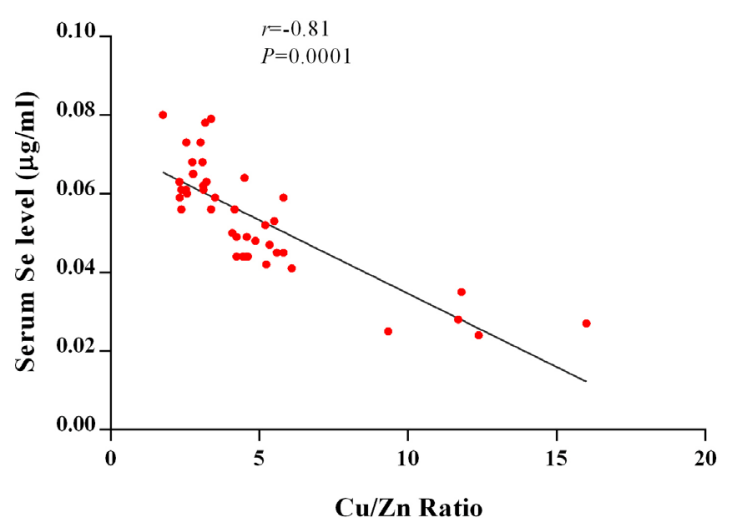

(a)

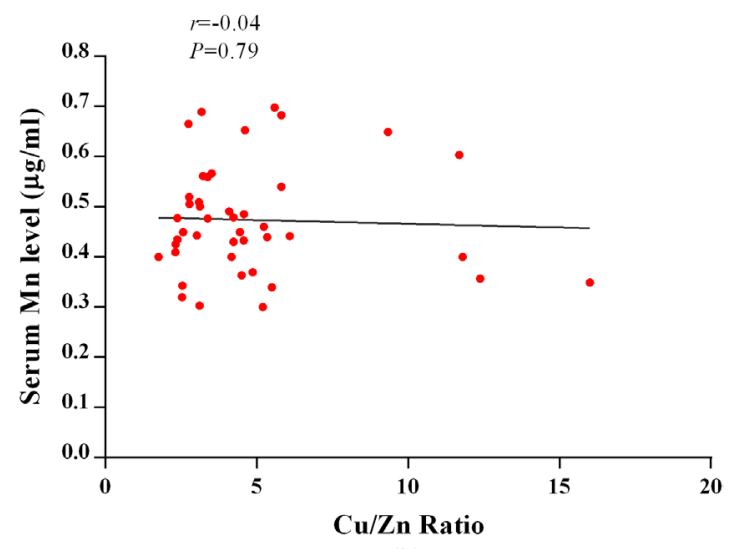

(b)

Figure 3. Correlation between $\mathrm{Cu} / \mathrm{Zn}$ ratio and serum levels of Se and $\mathrm{Mn}$ in patients with knee OA; $r=$ Spearman correlation coefficient; significance at $P<0.05$.

\section{Discussion}

The present study explored the associations between serum levels of 5 trace elements and the duration and severity of knee OA, demonstrating lower concentrations of $\mathrm{Zn}$, Se and $\mathrm{Mn}$ and higher concentrations of $\mathrm{Cu}$ and $\mathrm{Cu} / \mathrm{Zn}$ ratio in patients with knee OA compared with controls; in addition to strong association of disease duration and severity with serum concentrations of $\mathrm{Cu}, \mathrm{Zn}$ and Se. However, the association between $\mathrm{Mn}$ and $\mathrm{Mg}$ with the mentioned factors was not significant. Selenium is an important constituent of glutathione peroxidase enzyme and its deficiency resulting in a marked decline in glutathione peroxidase activity of many tissues, which leads to increased oxidative stress [14]. In the present study, serum Zn and Se concentrations were low in knee OA patients and negatively associated with the duration and severity of the disease, this is in good agreement with many results reported about $\mathrm{Zn}$ and Se status and many other diseases [15] [16]. In the presented study, the serum $\mathrm{Cu}$ level in patients with knee OA, confirmed the reports of some other investigators who have shown higher serum (or plasma) concentration of this element in the patients with OA and other inflammatory disorders including RA, compared to the control group [17] [18]. According to some other authors, this increased blood serum $\mathrm{Cu}$ concentration was even considered to be a marker of clinical activity of this disease [19]. Decreased levels of Se and the activity of selenium-dependent enzymes have also been studied in other diseases, including epilepsy, which showed a strong correlation between their reduction and severity of the disease [20]. Decreased serum Se levels in humans is unlikely to happen, but may be the etiological factor of some serious disorders such as Keshan disease (endemic cardiomyopathy) and Kashin-Beck disease (endemic osteoarthritis), which are successfully managed with Se supplements [21]. Understanding that Se is a cofactor of some enzymes with antioxidant activity; we can suggest that reduced serum levels of this element renders the individual prone to various damages mediated through oxidative stress [22]. Given that in evaluation of zinc and selenium levels various studies have shown some discrepancies, differences and changes in climate and minerals 
in soil, as well as type of race and other conditions included in the studies (for example, time of the year when samples were collected, and so forth) may lead to changes in these parameters in the serum, and eventually result in harmful states. Increased serum concentrations of Mn has been known to induce tissue damage, elevated levels of this trace element were reported to accumulate in the mitochondria [23]. In animal study, Mn toxicity has been involved in DNA fragmentation [24], which may be, in part, responsible for articular tissue damage, though the reported elevated levels showed poor correlation with the severity and duration of OA. Several limitations in the present study should be considered. First, the data revealed changes of trace element levels in peripheral blood (serum), and further researches still need to precisely determine whether such changes reflect relevant alterations in the articular tissue. Second, due to absence of some variables, including body mass index (BMI), smoking, dietary intakes and use of anti-inflammatory agents, potential confounding biases could not be excluded. However, some study did not find any association between drug doses, and smoking status, and the changes of several trace elements, including $\mathrm{Mn}, \mathrm{Se}, \mathrm{Fe}, \mathrm{Cu}$ and $\mathrm{Zn}$ [17]. Additionally, even if the socioeconomic and nutritional status of cases and controls are similar, it is still impossible to rule out the possibility that various genetic profiles might play a role in the pathogenicity and severity of knee OA [25]. The present study also has some significant advantages. The first strength is the simultaneous estimation of 5 trace elements under the same experimental conditions.

\section{Conclusion}

Patients with knee OA had higher levels of $\mathrm{Cu}$ and value of $\mathrm{Cu} / \mathrm{Zn}$ and lower levels of serum $\mathrm{Zn}$ and Se; these changes were potentially correlated with the duration and severity of disease. Zinc and selenium supplementation to reduce severity of knee OA should be further investigated.

\section{Acknowledgements}

The author thanks Sulaimani University for supporting the project.

\section{Conflict of Interest}

The author declares that there is no conflict of interest.

\section{References}

[1] Roush, J.K., McLaughlin, R.M. and Radlinsky, M.G. (2002) Understanding the Pathophysiology of Osteoarthritis. Veterinary Medicine, 97, 108-117.

[2] Haskin, C.L., Milam, S.B. and Cameron, I.L. (1995) Pathogenesis of Degenerative Joint Disease in the Human Temporomandibular Joint. Critical Review in Oral Biology and Medicine, 6, 248-277. http://dx.doi.org/10.1177/10454411950060030601

[3] He, G., Chen, X., Zhang, G., Lin, H., Li, R. and Wu, X. (2014) Detection of Urine C2C and Trace Element Level in Patients with Knee Osteoarthritis. Cell Biochemistry and Biophysics, 70, 475-479. http://dx.doi.org/10.1007/s12013-014-9943-2

[4] Krachler, M. and Domej, W. (2001) Clinical Laboratory Parameters in Osteoarthritic Knee-Joint Effusions Correlated to Trace Element Concentrations. Biological Trace Element Research, 79, 139-148. http://dx.doi.org/10.1385/BTER:79:2:139

[5] Shakibaei, M., Kociok, K., Forster, C., Vormann, J., Gunther, T., Stahlmann, R. and Merker, H.J. (1996) Comparative Evaluation of Ultrastructural Changes in Articular Cartilage of Ofloxacin-Treated and Magnesium-Deficient Immature Rats. Toxicology and Pathology, 24, 580-587. http://dx.doi.org/10.1177/019262339602400507

[6] King, D.E., Mainous, A.G., Geesey, M.E. and Woolson, R.F. (2005) Dietary Magnesium and C-Reactive Protein Levels. Journal of American College of Nutrition, 24, 166-171. http://dx.doi.org/10.1080/07315724.2005.10719461

[7] Henrotin, Y., Kurz, B. and Aigner, T. (2005) Oxygen and Reactive Oxygen Species in Cartilage Degradation: Friends or Foes? Osteoarthritis and Cartilage OARS, 13, 643-654. http://dx.doi.org/10.1016/j.joca.2005.04.002

[8] Kurz, B., Jost, B. and Schunke, M. (2002) Dietary Vitamins and Selenium Diminish the Development of Mechanically Induced Osteoarthritis and Increase the Expression of Antioxidative Enzymes in the Knee Joint of STR/1N Mice. Osteoarthritis and Cartilage OARS, 10, 119-126. http://dx.doi.org/10.1053/joca.2001.0489

[9] Gaby, A.R. (1999) Natural Treatments for Osteoarthritis. Alternative Medicine Reviews, 4, 330-341. 
[10] ACR (2000) American College of Rheumatology Subcommittee on Osteoarthritis Guidelines. Arthritis Rheumatism, 43, 1905-1915.

[11] Ahlback, S. (1968) Osteoarthrosis of the Knee: A Radiographic Investigation. Acta Radiologica Stockholm, 277, 7-72.

[12] Spector, T. and Hart, D. (1992) How Serious Is Knee Osteoarthritis? Annals of Rheumatic Diseases, 51, $1105-1106$. http://dx.doi.org/10.1136/ard.51.10.1105

[13] Leibovitz, A., Lubart, E., Wainstein, J., Dror, Y. and Segal, R. (2009) Serum Trace Elements in Elderly Frail Patients with Oropharyngeal Dysphagia. Journal of Nutrition Science and Vitaminology, 55, 407-411. http://dx.doi.org/10.3177/jnsv.55.407

[14] Shenkin, A. (2009) Selenium in Intravenous Nutrition. Gastroenterology, 137, 61-69. http://dx.doi.org/10.1053/j.gastro.2009.07.071

[15] Tulpar, S., Gunduz, Z., Sahin, U., Poyrazoglu, M.H., Dursun, I., Dusunse, R. and Bastug, F. (2014) Trace Elements in Children Suffering from Idiopathic Nephrotic Syndrome. Eurasian Journal of Medicine, 46, 187-191. http://dx.doi.org/10.5152/eajm.2014.36

[16] Mishra, O.P., Gupta, A.K., Prasad, R., et al. (2011) Antioxidant Status of Children with Idiopathic Nephrotic Syndrome. Pediatric Nephrology, 26, 251-256. http://dx.doi.org/10.1007/s00467-010-1696-6

[17] Yazar, M., Sarban, S., Kocyigit, A. and Isikan, U.E. (2005) Synovial Fluid and Plasma Selenium, Copper, Zinc, and Iron Concentrations in Patients with Rheumatoid Arthritis and Osteoarthritis. Biological Trace Element Research, 106, 123-132. http://dx.doi.org/10.1385/BTER:106:2:123

[18] Strecker, D., Mierzecki, A. and Radomska, K. (2013) Copper Levels in Patients with Rheumatoid Arthritis. Annals of Agricultural and Environmental Medicine, 20, 312-316.

[19] Milanino, R., Frigo, A., Bambara, L.M., Marrella, M., Moretti, U., Pasqualicchio, M., Biasi, D., Gasperini, R., Mainenti, L. and Velo, G.P. (1993) Copper and Zinc Status in Rheumatoid Arthritis: Studies of Plasma, Erythrocytes, and Urine, and Their Relationship to Disease Activity Markers and Pharmacological Treatment. Clinical and Experimental Rheumatology, 11, 271-281.

[20] Shams, S., Ashrafi, M., Noori, M., Irani, H., Ashtiani, M. and Mohseni, A. (2007) Selenium and Glutathione Peroxidase Deficiency in Epileptic Children. Iran Journal of Pediatrics, 17, 173-178.

[21] Thomson, C.D. (2004) Assessment of Requirements for Selenium and Adequacy of Selenium Status: A Review. European Journal of Clinical Nutrition, 58, 391-402. http://dx.doi.org/10.1038/sj.ejcn.1601800

[22] Shin, E.J., Jeong, J.H., Chung, Y.H., Kim, W.K., Ko, K.H., Bach, J.H., et al. (2011) Role of Oxidative Stress in Epileptic Seizures. Neurochemistry International, 59, 122-137. http://dx.doi.org/10.1016/j.neuint.2011.03.025

[23] Bowman, A.B., Kwakye, G.F., Herrero-Hernandez, E. and Aschner, M. (2011) Role of Manganese in Neurodegenerative Diseases. Journal of Trace Elements in Medicine and Biology, 25, 191-203. http://dx.doi.org/10.1016/j.jtemb.2011.08.144

[24] Malecki, E.A. (2001) Manganese Toxicity Is Associated with Mitochondrial Dysfunction and DNA Fragmentation in Rat Primary Striatal Neurons. Brain Research Bulletin, 55, 225-228. http://dx.doi.org/10.1016/S0361-9230(01)00456-7

[25] Chan, S., Gerson, B. and Subramaniam, S. (1998) The Role of Copper, Molybdenum, Selenium, and Zinc in Nutrition and Health. Clinical Laboratory Medicine, 18, 673-685. 